\title{
Medial triceps brachii free flap in reconstructive surgery: a prospective study in eight patients
}

\author{
Anaïs Delgove $\cdot$ Franck Marie Leclère $\cdot$ \\ Federico Villani · Gael Piquilloud · Ali Mojallal • \\ Vincent Casoli
}

Received: 30 March 2014 / Published online: 1 January 2015

(c) Springer-Verlag Berlin Heidelberg 2014

\begin{abstract}
Introduction In this study, we present a prospective series of medial triceps free flaps for ankle and foot complex defects coverage and discuss its numerous advantages.

Materials and methods Between January 2011 and December 2012, eight patients, two women and six men underwent medial triceps brachii (MTB) free flap procedure to cover defects localized at the ankle and foot in our department. Patient mean age was $37.3 \pm 15.2$ years at the time of surgery (range of 13-53 years). Mean defect size to be covered was $21.8 \pm 9.9 \mathrm{~cm}^{2}$. The bone was exposed at the level of the calcaneum in six cases, at
\end{abstract}

A. Delgove and F. M. Leclère contributed equally to this study.

Electronic supplementary material The online version of this article (doi:10.1007/s00402-014-2102-9) contains supplementary material, which is available to authorized users.

A. Delgove · F. M. Leclère $(\varangle) \cdot$ V. Casoli

Plastic Surgery and Burns Unit, University Hospital of Bordeaux FX Michelet Center, Place Amelie Raba Leon, 33076 Bordeaux, France

e-mail: franckleclere@yahoo.fr

F. M. Leclère

Department Hand and Plastic Surgery, INSELSPITAL Bern

Bern University, Bern, Switzerland

F. Villani

Department Plastic Surgery, IRCCS Policlinico San Donato San

Donato Milanese, Milan, Italy

G. Piquilloud

Department Plastic Surgery, CHAL Hôpital d'Annemasse,

Annemasse, France

A. Mojallal

Department Plastic Surgery Edouard Herriot Hospital,

University of Lyon, Lyon, France the level of the forefoot in one case, and at the level of the lateral malleolus in one case. Special attention was accorded to intra-operative findings. Flap survival and complications on both the donor and recipient site were prospectively evaluated.

Results Mean MTB flap raising time was $51.3 \pm 6.0 \mathrm{~min}$. All the flaps survived and there was no partial flap necrosis. A skin graft was performed after a mean time of $11.8 \pm 2.1$ days post-operative. The mean follow-up was $18.1 \pm 3.8$ months. Complications at the donor site level included one hematoma and a case of hypertrophic scar. Complete healing of both the donor and recipient sites was achieved in all cases.

Conclusions MTB free flap appears to be a useful option for covering small to medium defects in lower limb extremities. Due to the constant anatomy of the MTB nerve, we suggest that the flap could also be used as an innervated free flap for small or medium muscular reanimation such as sequelae of forearm and hand muscle impairment, or facial palsy.

Keywords Free Flap · Ankle - Cankle - Forefoot - Free medial triceps flap $\cdot$ Triceps $\cdot$ Flap

\section{Introduction}

Open wounds and defects in the lower extremity result from trauma, tumor resection, and chronic diseases such as peripheral vascular disease and diabetes [1]. The goal of lower extremity reconstruction is the coverage of defects to give patients a healed wound and to let them resume their life, ambulate, and go back to work while preventing amputation. Hence, the great importance of reconstructive surgical techniques for covering lower extremity defect to 
Table 1 Patients' demographics

\begin{tabular}{llll}
\hline N & Sex & Age & Nicotine \\
\hline $\mathbf{1}$ & M & 53 & + \\
$\mathbf{2}$ & F & 24 & - \\
$\mathbf{3}$ & F & 42 & - \\
$\mathbf{4}$ & M & 25 & + \\
$\mathbf{5}$ & M & 52 & + \\
$\mathbf{6}$ & M & 13 & - \\
$\mathbf{7}$ & M & 52 & + \\
$\mathbf{8}$ & M & 37 & - \\
\hline
\end{tabular}

restore the patients' physical, social, and economical life back to its normal limits [2-6].

Since the first work of Jacobson and Suarez, microsurgery has steadily developed [7-13] and microsurgical transfer of muscle is now commonly used for the coverage of difficult wounds at the ankle and foot level. Most common procedures include gracilis transfer [14], latissimus dorsi [15], serratus anterior, and rectus abdominis transfer. However, the most common complication of these procedures is the bulky aspect of the flap at long-term follow-up.

To overcome these difficulties, other teams have proposed smaller muscular flaps including pyramidalis muscle [16], anconeus muscle [17], and iliacus muscle [18]. Since our anatomical study [19] and first case report [20], we have used the free medial triceps brachii (MTB) because its smaller size and plasticity both match the surgical defect and avoid bulky aspect at long-term follow-up.

In this article, we present a prospective series of MTB free flaps for ankle and foot complex defects coverage and discuss its numerous advantages. We reviewed the final aspects of the lower extremities and the complications. Our results are discussed and compared to the current literature.

\section{Materials and methods}

Patients

This prospective clinical study protocol was performed following the ethical guidelines of the University of Bordeaux and conducted on eight patients. Inclusion criteria were: patients of all ages, of both sexes, operated on between January 2011 and December 2012, who underwent MTB free flap procedure to cover defect with osteomyelitis localized at the ankle and foot level in our department. The eight patients, two women and six men, had a mean age of $37.3 \pm 15.2$ years at the time of surgery (range of 13-53 years) (Table 1).

\section{Etiologies}

Etiologies of the defect was traumatic in three patients, pressure shore in one case, gun shot in two patients, diabetes in one case, and iatrogenic in one patient (Table 2). Mean defect size was $21.8 \pm 9.9 \mathrm{~cm}^{2}$ (range of $9-37.5 \mathrm{~cm}^{2}$ ). The bone was exposed at the level of the calcaneum in six cases, at the level of the forefoot in one case, and at the level of the lateral malleolus in one case. The defects were chronic in four cases, and acute in the remaining four cases. The involved lower extremity was right in four cases, and the left in four cases.

\section{Surgical technique}

The MTB flap was always raised on the non-dominant side of the patient [20]. The operative field was prepared with drapes around the shoulder. This was anteriorly flexed, with the elbow at a right angle, using a simple armrest. The depression between the lateral and long head of the triceps

Table 2 Origin and size of the defects covered in our series

\begin{tabular}{|c|c|c|c|c|c|c|}
\hline $\mathrm{N}$ & Type & Origin & $\begin{array}{l}\text { Delay } \\
\text { before } \\
\text { surgery }\end{array}$ & Localization & $\begin{array}{l}\text { Size } \\
\left(\mathrm{cm}^{2}\right)\end{array}$ & Bacteriology \\
\hline 1 & Chronic & Gun shot & 21 months & Calcaneum & 17.5 & $\begin{array}{l}\text { Sphingobacterium spiritivorum, Pseudomonas aeruginosa, Serratia } \\
\text { marcescens, Enterococcus faecium, Methicillin-resistant staphylococcus } \\
\text { epidermidis, Escherichia coli, Candida parapsilosis }\end{array}$ \\
\hline 2 & Chronic & Pressure shore & 10 years & Calcaneum & 24 & Methicillin-resistant staphylococcus epidermidis, Proteus mirabilis \\
\hline 3 & Acute & Iatrogenic & 26 days & Calcaneum & 9 & Methicillin-sensitive staphylococcus aureus, Streptococcus agalactiae \\
\hline 4 & Acute & $\begin{array}{l}\text { Open fracture } \\
\text { car accident }\end{array}$ & 75 days & Calcaneum & 15.75 & Methicillin-sensitive staphylococcus aureus \\
\hline 5 & Acute & $\begin{array}{l}\text { Open fracture } \\
\text { boat accident }\end{array}$ & 75 days & Ankle & 37.5 & Proteus, Escherichia coli \\
\hline 6 & Acute & Gun shot & 5 months & Forefoot & 31.5 & Pseudomonas lugdunensis, Bacillus cereus \\
\hline 7 & Chronic & Diabetic & 3 years & Calcaneum & 12 & Methicillin-sensitive staphylococcus aureus \\
\hline 8 & Chronic & Car accident & 14 years & Calcaneum & 27 & Methicillin-sensitive staphylococcus aureus \\
\hline
\end{tabular}



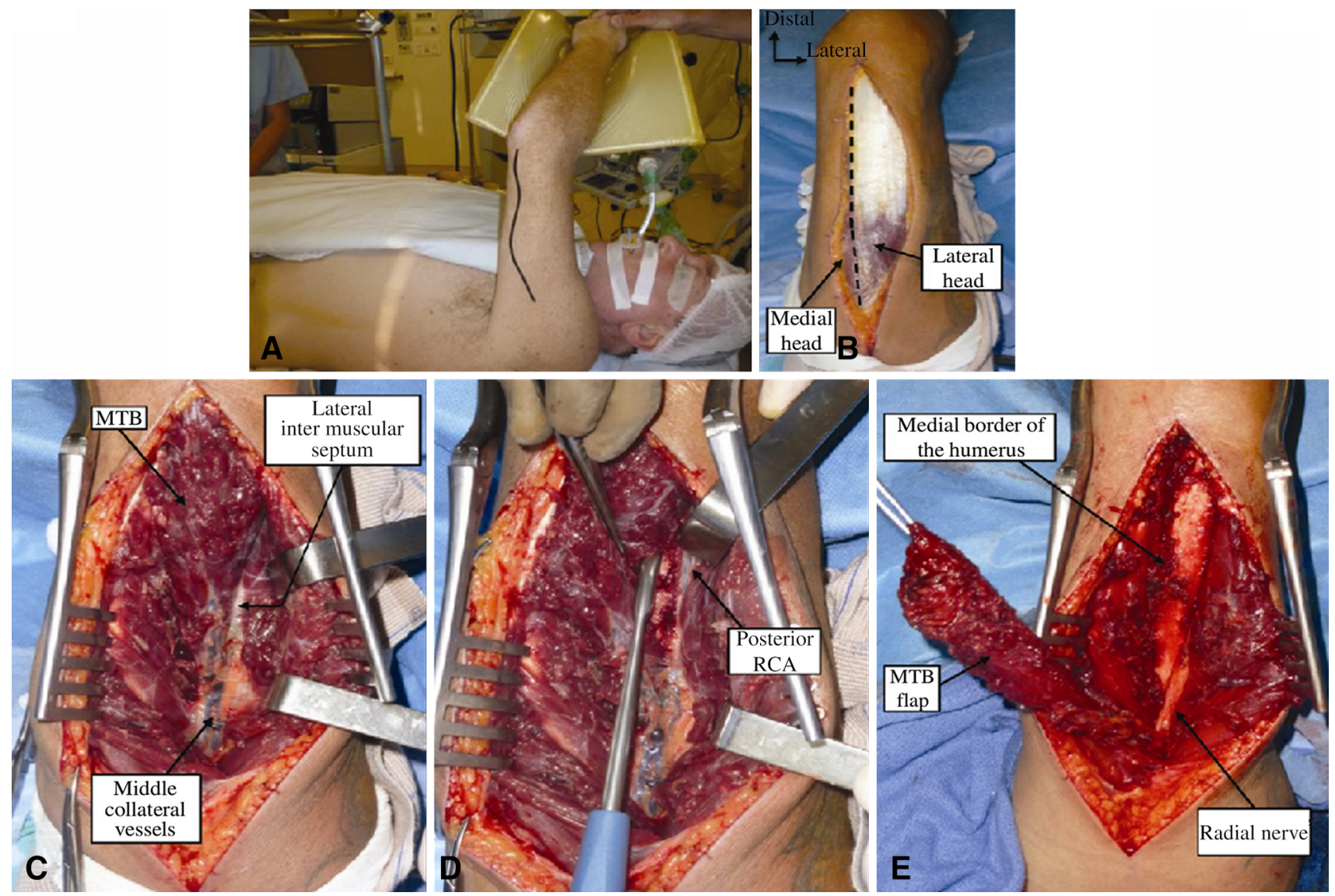

Fig. 1 a Installation: shoulder anteriorly flexed, elbow at a right angle; $\mathbf{b}$ The tendinous part of the triceps is exposed and incised along its medial border; c The long and lateral heads are both retracted, showing the MTB and its pedicle; a The posterior RCA is left laterally. The flap is dissected from the posterior aspect of the humerus with a rugine; e Medially, the flap is harvested along the medial border of the humerus. The MTB is isolated on its pedicle

should be limited to the medial border of the humerus; the ulnar nerve was not visualized during the dissection. One or two small collateral branches from medial collateral (MC) vessels for the long head were carefully ligated. Proximally, retractors were placed on the bellies of the lateral and long heads, allowing vessels and nerves to be exposed for dissection until the radial nerve groove. The MC pedicle was dissected and separated from the radial nerve and its sensitive branches, following it to its origin at the deep brachii artery (DBA). A few proximal muscle fibers were sectioned between the MC pedicle and the humerus allowing for full flap mobilization. To lengthen the pedicle, RC vessels were ligated at their origin from the deep brachii (DB) vessels, including those as the main pedicle.

The flap isolated on its pedicle was then harvested (Fig. 2). Interrupted, absorbable sutures were used between the lateral and long bellies, as well as an overlapping, continuous suture to restore the triceps muscle and tendon continuity. Primary skin closure of the cutaneous incision was performed by intra-dermic absorbable suture. using rugine and bipolar electrocautery. This dissection 


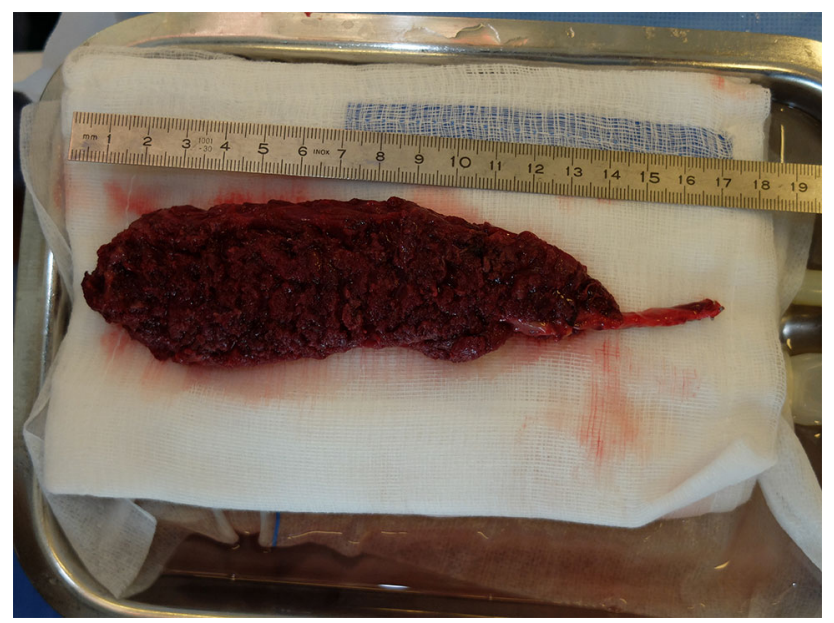

Fig. 2 The MTB flap and its pedicle (black arrow)

\section{Post-operative care}

At the donor site, a compressive dressing was placed for $48 \mathrm{~h}$ and the arm was kept in an elevated position on a pillow. Assessment of the flap was performed every hour using the following criteria: color, temperature, and turgor. Post-operative anticoagulation included 4,000 UI Anti-Xa/0.4 mL for the first two weeks post-procedure and Aspirin (Aspégic $250 \mathrm{mg} \mathrm{PO}$ ) for the first three months post-procedure. Post-operative treatment included two weeks of intra-venous antibiotics, followed by four weeks of oral antibiotics. The patients were allowed partial weight bearing and rehabilitation of the lower limb according to the progression of bone healing. Rehabilitation of the upper limb started one week after the procedure.

\section{Intra-operative assessment}

Mean time necessary to raise the MTB flap was recorded each time. Intra-operative complications were systematically registered. Length, width, thickness, and total surface of the medial head of the MTB were registered precisely. Pedicle length and diameters of the vessels were also precisely measured at $40 \times$ magnification.

\section{Outcomes assessment}

For each follow-up, complications were carefully recorded both at the donor and recipient site levels. At the donor site level, special attention was paid to post-operative neurologic evaluation of the upper limb. Mean time between the free flap procedure and the definitive coverage with mesh graft was registered in each case.
Measured parameters

In this study, eight patients with defects at the ankles and foot levels underwent coverage with medial brachii free flap. Data analysis was performed using SPSS program (SPSS v. 22.0). Data are presented as mean \pm standard error of the mean.

\section{Results}

Intra-operative findings

Mean flap raising time was $51.3 \pm 6.0 \mathrm{~min}$. There were no intra-operative complications. Intra-operative findings are reported in Table 3: The mean length of the medial head of the triceps brachii was $11.2 \pm 1.7 \mathrm{~cm}$ (range 9-14 cm). Mean width of the flap was $3.6 \pm 0.5 \mathrm{~cm}$ (range 3.0-4.5). Mean flap thickness was $2.1 \pm 0.2 \mathrm{~cm}$ (range 1.8-2.4 cm). Total flap surface was $41.1 \pm 12.7 \mathrm{~cm}^{2}$ (range $27-63 \mathrm{~cm}^{2}$ ). The mean pedicle length was $1.9 \pm 1.1 \mathrm{~cm}$. The mean artery and vein diameters were, respectively, $1.1 \pm 0.1$ and $1.2 \pm 0.1 \mathrm{~mm}$.

Complications at the donor site

One hematoma occurred at the donor site on day two postsurgery, requiring a tight dressing. Three months after surgery, one case of hypertrophic scar occurred at the donor site. A compressive silicon garment was used for this. An extension range of $0^{\circ}$ was measured for all patients. No complaints about strength loss and no neurologic deficits were reported.

Flap outcomes (Figs. 3, 4)

All the flaps survived and there was no flap partial necrosis. A skin graft was performed after a mean time of $11.8 \pm 2.1$ days (range 8-15 days) post-operative. The mean follow-up was $18.1 \pm 3.8$ months. Complete healing of recipient sites was achieved in all cases.

\section{Discussion}

In this study, eight patients with defects at the ankle and foot level underwent coverage with MTB free flap. All the flaps survived and a complete healing of both the donor and recipient sites was achieved in all cases. Complications at the donor site level included one hematoma and a case of hypertrophic scar.

A number of surgical options have been described that treat traumatic loss of substance, or chronically infected 
Table 3 Dimensions and outcomes of the medial triceps brachii free flap procedures in our series

\begin{tabular}{llllllllll}
\hline N & $\begin{array}{l}\text { Flap } \\
\text { length } \\
(\mathrm{cm})\end{array}$ & $\begin{array}{l}\text { Flap } \\
\text { width } \\
(\mathrm{cm})\end{array}$ & $\begin{array}{l}\text { Flap } \\
\text { thickness } \\
(\mathrm{cm})\end{array}$ & $\begin{array}{l}\text { Flap } \\
\text { surface } \\
\left(\mathrm{cm}^{2}\right)\end{array}$ & $\begin{array}{l}\text { Pedicle } \\
\text { size } \\
(\mathrm{cm})\end{array}$ & $\begin{array}{l}\text { Vessels } \\
\text { diameter } \\
(\mathrm{A} / \mathrm{V}) \\
(\mathrm{mm})\end{array}$ & $\begin{array}{l}\text { Flap } \\
\text { raising } \\
\text { time } \\
(\mathrm{min})\end{array}$ & $\begin{array}{l}\text { Flap } \\
\text { survival } \\
(1 / 0)\end{array}$ & Complications \\
\hline $\mathbf{1}$ & 11 & 3.5 & 2.2 & 38.5 & 1.5 & $1.1 / 1.4$ & 52 & 1 & - \\
$\mathbf{2}$ & 10 & 3.5 & 1.9 & 35 & 1.5 & $1.0 / 1.1$ & 55 & 1 & $\begin{array}{l}\text { Hypertrophic } \\
\text { scar at the } \\
\end{array}$ \\
$\mathbf{3}$ & 10 & 3 & 1.9 & 30 & 1 & $1.0 / 1.2$ & 44 & 1 & - donor site \\
$\mathbf{4}$ & 10.5 & 3.5 & 1.8 & 36.6 & 1.5 & $1.3 / 1.1$ & 56 & 1 & - \\
$\mathbf{5}$ & 12 & 3.5 & 2.1 & 42 & 2 & $1.2 / 1.4$ & 44 & 1 & - \\
$\mathbf{6}$ & 13 & 4 & 2.1 & 52 & 2 & $1.1 / 1.2$ & 61 & 1 & - \\
$\mathbf{7}$ & 9 & 3 & 2 & 27 & 4.5 & $1.0 / 1.1$ & 47 & 1 & - \\
$\mathbf{8}$ & 14 & 4.5 & 2.4 & 63 & 1 & $1.1 / 1.2$ & 51 & 1 & Hematoma at \\
& & & & & & & & & the donor \\
site
\end{tabular}
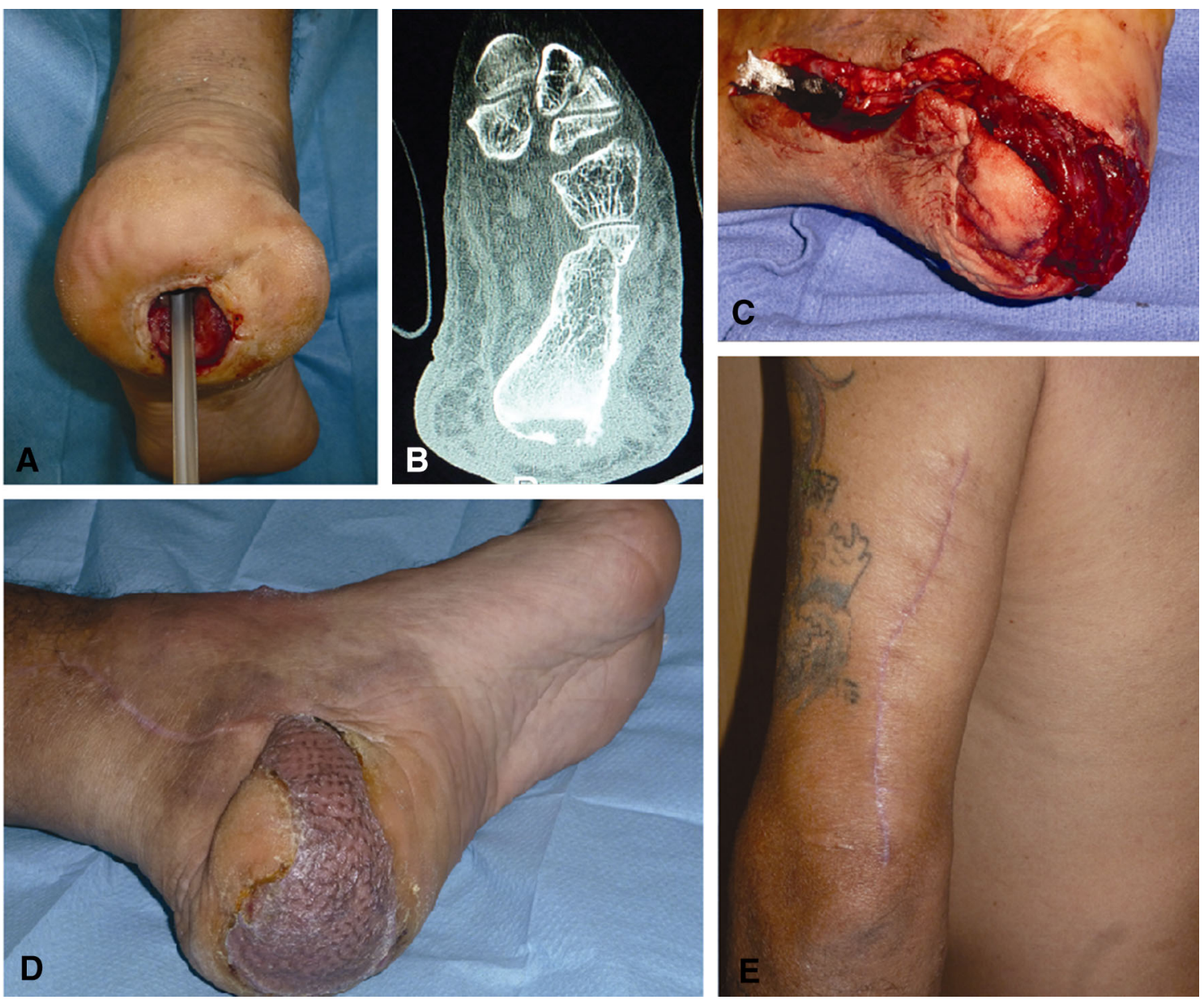

Fig. 3 a, b A 52-year-old man presented a diabetic chronic wound involving the left calcaneal bone (Patient 7 of the series). The patient was referred to plastic surgery for soft tissue coverage and treatment of chronic osteomyelitis. After soft tissue and bone debridement, he presented a $4 \times 3 \mathrm{~cm}$ soft tissue defect; c The MTB flap was designed and transferred microsurgically as well. The MC vessels were anastomosed to the posterior tibial vessels while a meshed skin graft was applied to the flap; d Four months later, the patient was walking almost normally and demonstrated a well-healed wound with only a mild contour deformity. e The donor site healed uneventfully 

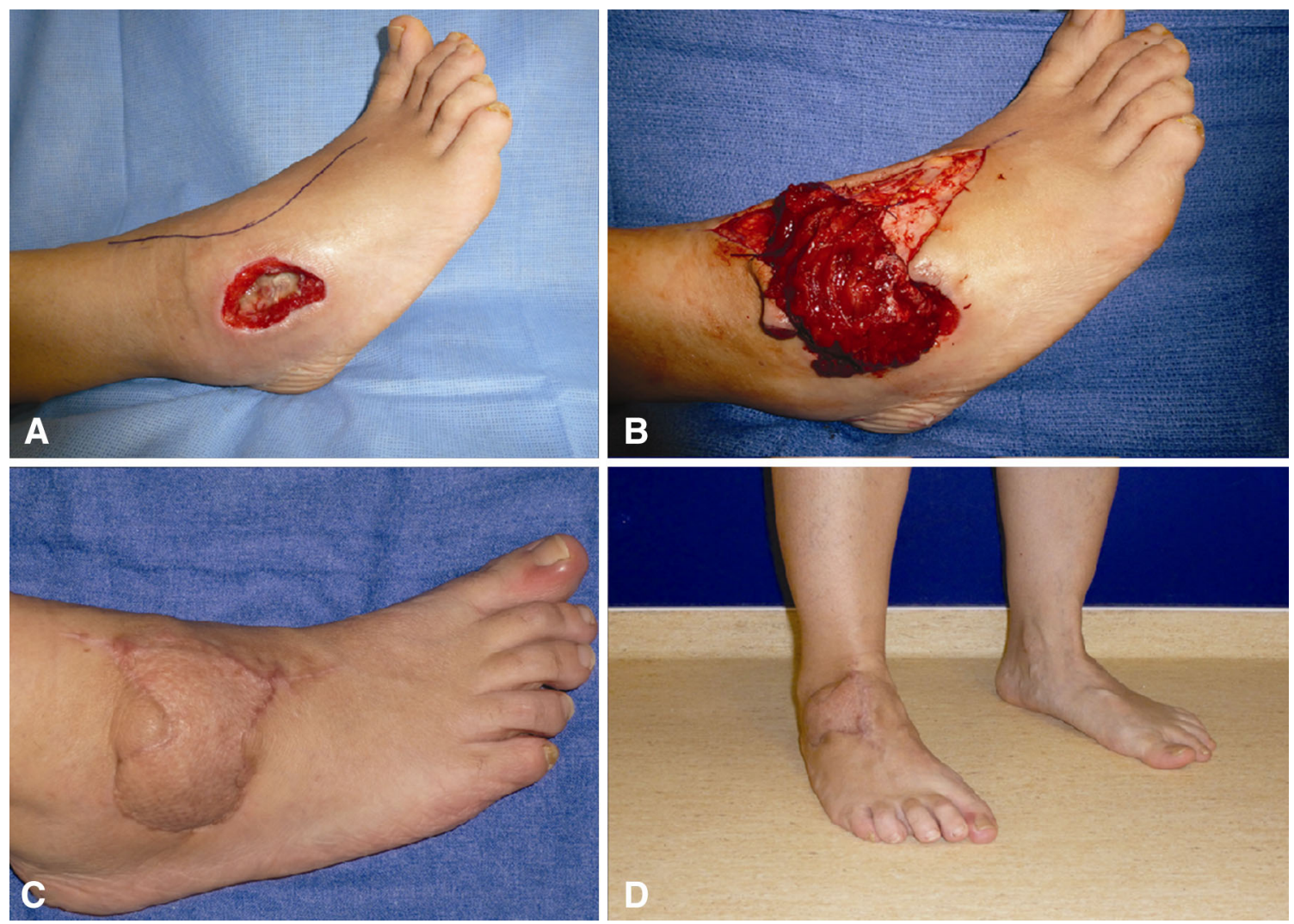

Fig. 4 a A 42-year-old woman underwent orthopedic surgery for a calcaneal tumor (Patient 3 of the series). At two weeks follow-up, the wound broke down and exposed the bony structures. The patient was referred to plastic surgery to treat osteomyelitis. After debridement, she presented a $3.5 \times 3.5 \mathrm{~cm}$ soft tissue defect; b A medial triceps

muscle flap was designed and transferred microsurgically. The MCA was anastomosed to the dorsalis pedis artery and the flap was covered by a split-thickness skin graft; c, d Five months later, she demonstrated a completely healed wound with no contour abnormality

wounds of the foot and ankle, including pedicled or free muscle and fasciocutaneous flaps [21]. In cases of severe trauma injury to the lower leg and foot, pedicled flaps should be considered, because the vascular axes are interrupted in most patients. However, if no local flap is suitable due to poor quality of the surrounding tissue, and the main arteries have been preserved, a free flap would be indicated. In particular, fasciocutaneous and muscular free flaps have been used to fill defects with well-vascularized tissue [22, 23]. Muscular flaps have better blood flow, expediting bone healing in early phases of repair [22-25]. In a recent review of the literature, Chan et al. concluded that in open fractures of the lower limb, where the bone is exposed, the muscle conforms better to complex defects and its plasticity helps to obliterate the dead space [21].

All of our patients had deep defects of the ankle and foot, with bone exposure and positive bacteriological examination, requiring that they be obliterated with wellvascularized tissue; therefore, a muscular free flap seemed to be the best option. As detailed in the introduction section, different surgical options do exist in the use of free muscle flap, but most of them have drawbacks, including a

flap that is too bulky and functional deficit of the donor site. Instead of using part of a large muscle (e.g., gracilis [14], latissimus dorsi [15], serratus anterior, and rectus abdominis) and affecting its function, smaller muscular flaps including pyramidalis [16], anconeus [17], or iliacus [18] have been proposed.

Following our previous anatomical studies as well as our previous clinical experience with the pedicled flap [19] and first case report [19], we considered several options and then decided to use the medial head of triceps free flap in patients of the present study. Its pedicle (middle collateral vessels) has been shown to be constant. The flap widens from its pedicle to its distal part. Its average size was $41 \mathrm{~cm}^{2}$ and $2 \mathrm{~cm}$ in thickness: it fitted well in the recipient defects, on average $22 \mathrm{~cm}^{2}$, but $4-5 \mathrm{~cm}$ in depth. Due to plasticity of the muscle, the flap was easy to model and then fill the wound defect. In addition, we observed no necrosis of the flap, so that the overlying graft was accepted each time. Concerning the donor site, the medial head of the triceps muscle does not exceed $25 \%$ of the total mass of the muscle [19] and its precise role in overall muscular function is unclear: there was no complaint about 
forearm extension impairment in treated patients; nevertheless, the flap was harvested on the non-dominant arm. Both the long and lateral muscle (and their portion of the common tendon) can be easily closed. The ulnar nerve, which is medially located, was never exposed in our dissection, minimizing the risk of nerve injury. The radial nerve was clearly seen and easily preserved during pedicle dissection. No sensory loss was reported at the donor site. Drawbacks of the MTB free flap include (1) its small size and short pedicle, making it suitable exclusively for limited defects; (2) the anatomy of the region, requiring an experienced surgeon; and (3) the visibility of the scar of the donor site, especially in female patients.

Due to the constant anatomy of the MTB nerve, we suggest that the flap could also be used as an innervated free flap for small or medium muscular reanimation such as sequelae of forearm and hand muscle impairment, or facial palsy. Moreover, the medial head of the triceps muscle has a strong tendon, which could be partially harvested for this purpose. It would represent an alternative option to using parts of larger muscles (e.g., latissimus dorsi [26], rectus femoris [27] or gracilis [28]) or similar small muscle flaps (e.g., pectoralis minor [29], serratus anterior [30], coracobrachialis muscle [31].

Despite the innovative aspect and the relative long follow-up of our series, three methodological limitations remain. Firstly, this study was limited by its nature as a non-controlled analysis. It would be of interest to compare precisely the MTB flap with similar small muscle flaps. Moreover, the number of patients was small. However, at the beginning of our clinical experience, we have decided to limit the use of the MTB flap to precise defect localization and defect sizes. Actually as discussed above, we have decided to extend the indications of this flap. Finally, this study did not focus on the donor site morbidity, e.g., the post-operative strength of the triceps in comparison to the healthy side. This will be reported in another study focusing on the donor site [32].

\section{Conclusion}

The MTB free flap appears to be a useful option in covering small to medium defects in lower limb extremities. Due to the constant anatomy of the MTB nerve, we suggest that the flap could also be used as an innervated free flap for small or medium muscular reanimation such as sequelae of forearm and hand muscle impairment, or facial palsy.

Conflict of interest The authors declare that there is no conflict of interest.

\section{References}

1. Parrett BM, Pribaz J (2010) Lower extremity reconstruction. Rev med clin condes 21:66-75

2. Ramkrishna R, Kulkarni BD (2013) Procedures used for reconstruction of lower extremity soft tissue defect. Indian J Appl Res 8:383-386

3. Hierner EL, Corterier C, Hierner R (2013) Lateral supramalleolar flaps for reconstruction in the ankle and foot. Oper Orthop Traumatol 25:122-130

4. Giessler GA, Schmidt AB (2013) Muscular and osteomuscular peroneus brevis flaps. Oper Orthop Traumatol 25:131-144

5. Kneser U, Beier JP, Dragu A, Arkudas A, Horch RE (2013) Peroneal artery perforator flap. Oper Orthop Traumatol 25:170-175

6. Knobloch K, Herold C, Vogt PM (2012) Free latissimus dorsi flap transfer for reconstruction of soft tissue defects of the lower extremity. Oper Orthop Traumatol 24:122-130

7. Leclère FM, Schoofs M, Buys B, Mordon SR (2010) Outcomes after 1.9-microm diode laser-assisted anastomosis in reconstructive microsurgery: results in 27 patients. Plast Reconstr Surg 125:1167-1175

8. Leclère FM, Schoofs M, Buys B (2011) Mordon SR (2011), $1.9 \mu \mathrm{m}$ diode laser assisted vascular microanastomoses: experience in 40 clinical procedures. Lasers Surg Med 43:293-297

9. Leclère FM, Schoofs M, Auger F, Mordon S (2010) Blood flow assessment with magnetic resonance imaging after $1.9 \mu \mathrm{m}$ diode laser assisted microvascular vein anastomosis. Lasers Surg Med 42:299-305

10. Wang L, Fu J, Li M, Han D, Yang L (2013) Repair of hand defects by transfer of free tissue flaps from toes. Arch Orthop Trauma Surg 133:141-146

11. Leclère FM, Schoofs M, Auger F, Mordon S (2011) Blood flow assessment with magnetic resonance imaging after 1.9 mum diode laser assisted arterial micronastomoses. Ann Chir Plast Esthet 56:540-547

12. Leclère FM, Martinot V, Schoofs M, Mordon S (2011) Thirty years of laser-assisted microvascular anastomosis (LAMA): what are the clinical perspectives? Neurochirurgie 57:1-8

13. Leclère FM, Schoofs M, Mordon S (2011) Historical review and future orientations of the conventional vascular microanastomoses. Ann Chir Plast Esthet 56:232-240

14. Hallock GG (1999) Minimally invasive harvest of the gracilis muscle. Plast Reconstr Surg 104:801-805

15. Tobin GR, Moberg AW (1981) The split latissimus dorsi myocutaneous flap. Ann Plast Surg 7:272-280

16. Van Landuyt K, Hamdi M, Blondeel P, Monstrey S (2003) The pyramidalis muscle free flap. Br J Plast Surg 56:585-592

17. Hwang K, Han JY, Chung IH (2004) Topographical anatomy of the anconeus muscle for use as a free flap. J Reconstr Microsurg 20:631-636

18. Medalie DA, Llull R, Heckler F (2011) The iliacus muscle flap: an anatomical and clinical evaluation. Plast Reconstr Surg 127:1553-1560

19. Piquilloud G, Villani F, Casoli V (2011) The medial head of the triceps brachii. Anatomy and blood supply of a new muscular free flap: the medial triceps free flap. Surg Radiol Anat 33:415-420

20. Leclère FM, Casoli V (2014) Reconstruction of a traumatic plantar foot defect with a new free flap : the medial triceps brachii free flap. JCLT [Epub ahead of print]

21. Villani F, Piquilloud G, Casoli V (2012) The medial head of triceps brachii: a muscular flap. J Plast Reconstr Aesthet Surg 65:263-264

22. Chan JK, Harry L, Williams G, Nanchahal J (2012) Soft-tissue reconstruction of open fractures of the lower limb: muscle versus fasciocutaneous flaps. Plast Reconstr Surg 130:284-295 
23. Harry LE, Sandison A, Pearse MF, Paleolog EM, Nanchahal J (2009) Comparison of the vascularity of fasciocutaneous tissue and muscle for coverage of open tibial fractures. Plast Reconstr Surg 124:1211-1219

24. Liu R, Schindeler A, Little DG (2010) The potential role of muscle in bone repair. J Musculoskelet Neuronal Interact 10:71-76

25. Gonzalez M, Weinzweig N (2005) Muscle flaps in the treatment of osteomyelitis of the lower extremity. J Trauma-Injury Infect Critical Care 58:1019-1023

26. Wei W, Zuoliang Q, Xiaoxi L et al (1999) Free split and segmental latissimus dorsi muscle transfer in one stage for facial reanimation. Plast Reconstr Surg 103:473-480

27. Yang D, Morris SF (1999) Neurovascular anatomy of the rectus femoris muscle related to functioning muscle transfer. Plast Reconstr Surg 104:102-106

28. Chuang DC, Mardini S, Lin SH, Chen HC (2004) Free proximal gracilis muscle and its skin paddle compound flap transplantation for complex facial paralysis. Plast Reconstr Surg 113:126-132
29. MacQuillan A, Horlock N, Grobbelaar A, Harrison D (2004) Arterial and venous anatomical features of the pectoralis minor muscle flap pedicle. Plast Reconstr Surg 113:872-876

30. Godat DM, Sanger JR, Lifchez SD et al (2004) Detailed neurovascular anatomy of the serratus anterior muscle: implications for a functional muscle flap with multiple independent force vectors. Plast Reconstr Surg 114:21-29

31. Taylor GI, Cichowitz A, Ang SG, Seneviratne S, Ashton M (2003) Comparative anatomical study of the gracilis and coracobrachialis muscles: implications for facial reanimation. Plast Reconstr Surg 112:20-30

32. Leclère FM, Casoli V. Medial Triceps Brachii Free Flap in Reconstructive Surgery: Donor Site Morbidity. In Review 